\title{
Assessment of the one hour adrenocorticotrophic hormone test in the diagnosis of attentuated 21-hydroxylase deficiency
}

\author{
V T Innanen, J M Vale
}

\begin{abstract}
Attenuated or partial 21-hydroxylase deficiency is one of several biochemical defects in steroid metabolism that can lead to hirsutism in young women after puberty. The diagnosis is made through the exaggerated response of $17 \alpha$ hydroxyprogesterone (17-OH) to adrenocorticotrophic hormone (ACTH). To provide reference data 72 mild to moderately hirsute patients aged 18 to 35 were studied (over two years) with the ACTH test. Four patients with an exaggerated response were found. The mean $( \pm 1 S D)$ for zero time was $2.4(0.96)$ $\mathrm{nmol} / 1$ and for the 60 minute time was $7 \cdot 2$ (2.04) $\mathrm{nmol} / 1$. A subpopulation was found with a significantly higher baseline at $6 \cdot 2$ (1.3) nmol/1 but a blunted 60 minute response at $8 \cdot 7(2 \cdot 5) \mathrm{nmol} / \mathrm{l}$. This is important because of the potential confusion arising from the known variability in baseline values in previously reported patients with partial 21-hydroxylase deficiency.

Extending the test to 90 minutes did not show further increase in the $17-\mathrm{OH}$ response to $\mathrm{ACTH}$, thus confirming the validity of the 60 minutes ACTH test. The cortisol response to ACTH was also studied. One patient with presumptive partial 21-hydroxylase deficiency overlapped in cortisol response with eight of the reference population. Theoretically, a blunted cortisol response would be expected because of the postulated enzyme block, and these results suggest that other steroid enzyme defects should also be considered when an exaggerated 17-OH response to $\mathrm{ACTH}$ is seen.
\end{abstract}

Idiopathic hirsutism is becoming a redundant diagnostic term as technological advances uncover subtle adrenal enzymatic and peripheral defects in androgen metabolism. One of these defects has been ascribed to a partial or attenuated form of adrenal 21hydroxylase deficiency. The diagnosis at present is presumptive and is made from the observation of an exaggerated $17 \alpha$-hydroxyprogesterone $(17-\mathrm{OH})$ response to the one hour adrenocorticotrophic hormone (ACTH) stimulation test. ${ }^{1}$

At present there are few clearly defined reference data available to laboratory personnel and clinicians on the $17-\mathrm{OH}$ response to ACTH. This type of information has previously been presented as part of a graph or nomogram. ${ }^{23}$ For example, the baseline values for the one hour ACTH test were not delineated in the work of New et al. ${ }^{3}$ We therefore used the stimulation test in 72 moderately hirsute women over two years and uncovered four patients with an increased or exaggerated response of $17-\mathrm{OH}$ to $\mathrm{ACTH}$. A reference range was derived from the nonresponders, and an apparent subgroup emerged with higher baseline values but a blunted response to ACTH. The cortisol response to ACTH was also studied and a comparison drawn between non-responders and responders to $\mathrm{ACTH}$

\section{Methods}

Each patient was given $0.25 \mathrm{mg}$ synthetic ACTH intravenously (Cortrosyn, Organon Canada Ltd, Ontario). Cortisol and $17 \alpha-$ hydroxyprogesterone were measured at baseline, 30, 60, and at 90 minutes. The injection was routinely performed at 09000915 hours. Cortisol was measured with a kit purchased from Clinical Assays (Cambridge, Massachusetts, USA). $17 \quad \alpha$-hydroxyprogesterone was measured using a tritiated radioimmunoassay kit from Radioassay Systems Laboratories, Carson, California at the MacMaster University Hospital Clinical Biochemistry Laboratory in Hamilton, Ontario. Interrun precision values for $17-\mathrm{OH}$ were $8.6^{\circ}{ }_{0}, 6.4^{\circ}{ }_{0}$, and $8.4 \%$ at control concentrations of $5.8,14.0$, and $39.0 \mathrm{nmol} / \mathrm{l}$, respectively $(n=40)$. Crossreactivity was $0.58^{\circ}{ }_{0}$ for $17 \alpha-\mathrm{OH}$ pregnenolone, $0.18 \%$ for progesterone, and $<0.01 \%$ for oestradiol, dehydroepiandrosterone sulphate (DHEAS) and testosterone.

Seventy two patients with mild to moderate hirsutism were studied. This included grades 1 to 3 , as defined by Ferriman and Gallwey, ${ }^{4}$ for the upper lip, chest, lower abdomen, forearm and leg. Their ages ranged from 18 to 35 . None of the patients was amenorrhoeaic although several menstruated only every two to three months. The hirsutism in all patients was postpubertal, and in no case was there evidence of virilisation. On pelvic examination none of the patients had evidence of enlarged ovaries. The patients were a sample representing as closely as possible the population to be tested, as previously recommended for reference studies. $^{56}$ 
The response of $17 \alpha-$ hydroxyprogesterone to ACTH in a reference population of moderately hirsute women aged 18 to 35. The time course is measured in minutes and has been followed to 90 minutes. The error bars represent the mean

( $\pm 1 S D)$ in nmol ll at each data point. Group II $(0-0, n=12)$ has $a$ higher baseline than group $I(\Delta-\Delta, n=56$; $p<0.001)$ but the 60 minute data point was not significantly different.

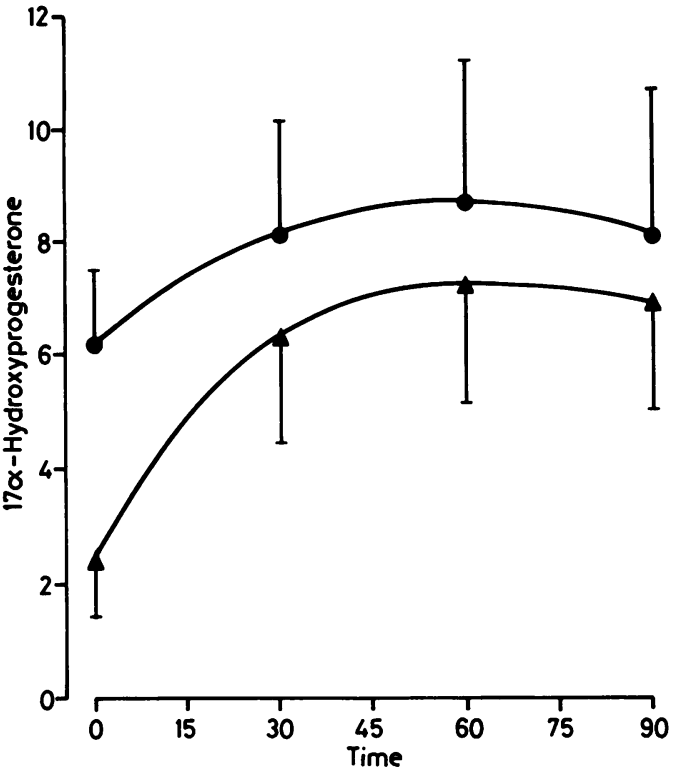

Results

The figure shows the increase in $17-\mathrm{OH}$ of 68 subjects with normal responses (nonresponders) to ACTH stimulation. Extending the test to 90 minutes did not result in increased values relative to 60 minutes. A subpopulation of patients had higher baseline values (group II, $\mathrm{n}=12, \mathrm{p}<0.001$ ) when compared with the main group of non-responders (group I, $\mathrm{n}=56$ ). Their response to ACTH seems to have been blunted as the 60 and 90 minutes $17-\mathrm{OH}$ values were not significantly different from those of the main group of nonresponders.

The table shows the reference data for the two subgroups of the 17-OH non-responders. For group $I(n=56)$ the zero time value for the mean (1 SD) was $2.4(0.96) \mathrm{nmol} / \mathrm{l}$ (range 0.48 $3.36)$ and the 60 minutes value was $7.2(2.04)$ (range $3 \cdot 12-11 \cdot 28)$. For group II $(n=12)$ the zero time value for the mean (1 SD) was 6.2 $(1 \cdot 3) \mathrm{nmol} / \mathrm{l}$ (range 3.6-8.8) and the 60 minutes value was $8.7(2.5)$ (range $3.7-13.7)$. The difference between the mean baseline values for groups I and II was significant $(p<0.001$, Student's $t$ test); the difference between the mean 60 minute values was not.

During the two years of the study we found four patients who responded to ACTH quite differently from the reference group (table).
The heterogeneity of the response has been noted before. ${ }^{23}$

We also studied the cortisol responses of the same groups of patients. For groups I and II the average baseline and 60 minute responses to ACTH were not significantly different (table). We subtracted the zero time values from the 60 minute values for cases 1 and 2 ( $\triangle$ values) and compared these with the same data derived from groups I and II. Although for cases 1 and 3 the $\triangle$ values were clearly less than the average for groups I and II, the $\Delta$ values from eight patients from groups I and II overlapped with those of case 2 (data not shown).

\section{Discussion}

The diagnosis of idiopathic hirsutism, by definition, denotes that the cause of the hirsutism has not been identified in a particular patient. In recent years the number of patients fitting this category has diminished in the light of recently identified defects in ovarian, adrenal, and peripheral androgen metabolism. Some examples are apparent attenuated defects in 21-hydroxylase ${ }^{1}, \quad 11$-hydroxylase, ${ }^{7}$ and 3 B-ol dehydrogenase, ${ }^{89}$ as well as inefficient peripheral metabolism of androgens. ${ }^{1011}$

Over two years we identified four patients with an exaggerated $17-\mathrm{OH}$ response to the $0.25 \mathrm{mg}$ ACTH stimulation test. We tentatively identified these patients as partially defective in 21-hydroxylase activity, as described by previous workers. ${ }^{23}$ In searching for these patients we analysed a total of 72 patients, of whom 68 did not respond to ACTH beyond $2 \mathrm{SD}$ of the mean. On inspection it became apparent that there was a subgroup with a significantly higher baseline $17-\mathrm{OH}$ than the remainder (figure, table). Their response to the ACTH test, however, was blunted, and this was not significantly different from the remainder of the non-responders. The clinical importance of this phenomenon is unclear at present. These patients were tested at the same time in the morning as the main groups, such that diurnal variation in endogenous ACTH secretion should not have accounted for a baseline difference, especially as there were no significant differences between groups I and II for baseline cortisol values (table).

As can be seen in the figure the $17-\mathrm{OH}$ response off at 60 minutes and is not signifi-

Reference values (mean $\pm 1 S D$ ) and range (2 SD) for $17 \alpha$-hydroxyprogesterone and cortisol for moderately hirsute women aged 18 to 35 at zero time and 60 minutes

\begin{tabular}{|c|c|c|c|c|}
\hline & \multicolumn{2}{|c|}{$17 \alpha$-hydroxyprogesterone (nmol/l) } & \multicolumn{2}{|l|}{ Cortisol (nmol/l) } \\
\hline & Time in minutes & & & \\
\hline & 0 & 60 & 0 & 60 \\
\hline $\begin{array}{l}\text { Reference group I } \\
\text { (non-responders) range } \\
\text { Reference group II } \\
\text { (non-responder-higher baseline) range } \\
\text { Case } 1 \\
\text { Case } 2 \\
\text { Case } 3 \\
\text { Case } 4\end{array}$ & $\begin{array}{l}2 \cdot 4(0 \cdot 96) \\
0 \cdot 48-3 \cdot 36 \\
6 \cdot 2(1 \cdot 3) \\
3 \cdot 6-8 \cdot 8 \\
19 \\
16 \\
7 \\
6\end{array}$ & $\begin{array}{l}7 \cdot 2(2 \cdot 04) \\
3 \cdot 12-11 \cdot 28 \\
8 \cdot 7(2 \cdot 5) \\
3 \cdot 7-13 \cdot 7 \\
219 \\
147 \\
63 \\
19\end{array}$ & $\begin{array}{l}409(146) \\
452(58) \\
550 \\
410 \\
450 \\
470\end{array}$ & $\begin{array}{l}940(140) \\
900(126) \\
790 \\
770 \\
630 \\
1050\end{array}$ \\
\hline
\end{tabular}

The numbers for case 1-4 represent data obtained from four patients in whom the $17 \alpha$-hydroxyprogesterone response to ACTH was exaggerated. 
cantly different at the 90 minute point. The appropriate cut off for the test seems to be 60 minutes, although in three of our patients, cases 1-3, the exaggerated response still seemed to be increasing at 90 minutes (data not shown). A substantial increase was sufficiently large to discriminate them from non-responders at 60 minutes. It would thus seem unnecessary to continue the ACTH test past 60 minutes, although this specific point has not been previously reported.

The reference ranges derived from our data can be seen in the table. For group $I(n=56)$, the baseline value $( \pm 1 \mathrm{SD})$ was $2.4(0.96)$ $\mathrm{nmol} / 1$ and $7 \cdot 2(2 \cdot 04) \mathrm{nmol} / \mathrm{l}$ for the 60 minute response. For subgroup II $(n=12)$ with the blunted response, the baseline value $( \pm 1 \mathrm{SD})$ was $6 \cdot 2(1 \cdot 3) \mathrm{nmol} / \mathrm{l}$ and $8 \cdot 7(2 \cdot 5) \mathrm{nmol} / 1$ for the 60 minute response. As is apparent, the reference ranges are well defined and will be of value in assessing stimulation data in the future. Cases 1-3 (table) represent examples of homozygous partial 21-hydroxylase deficiency while case 4 is a heterozygote for the condition as defined by the nomogram of New et al. ${ }^{3}$ Unfortunately, values for baseline 17-OH were not specifically delineated in New's study, and a bimodal aspect does not appear in the nomogram. The reference ranges presented in this report will be of future value in this regard.

The occurrence of a second group with higher baseline values is important because of the known variability of baseline values ${ }^{1}$ seen in patients with attenuated 21-hydroxylase deficiency. Their baseline values should not be confused with those patients showing a blunted 17-OH response.

We also studied the serum cortisol responses to ACTH in all of the patients to control and validate our injection procedures. The cortisol values seen in the table were also of interest as these patients are theoretically vulnerable to cortisol deficiency ${ }^{2}$ and therefore a blunted response to ACTH might be expected in these patients because of the postulated block. Although lower than most of the nonresponders, and certainly less than the average response of both groups I and group II (table), the response to ACTH at 60 minutes for case 2 (table) overlapped with that of eight of the nonresponders. This indicates either (i) that a compensatory mechanism is sufficient to prevent a blunted cortisol response, or (ii) that some other enzyme defect might have a role in some of the reported cases, and (iii) that a blunted cortisol response cannot be used as a screening device for 21-hydroxylase deficiency.

In respect of the second possibility, there is a paucity of work on biochemical analysis of downstream metabolites of $17 \alpha$-hydroxyprogesterone. 21-deoxycortisol is a good example of a downstream metabolite and it has been suggested as an alternative to $17-\mathrm{OH}$ in the diagnosis of 21-hydroxylase deficiency. ${ }^{12}$ Other enzyme defects could conceivably result in an exaggerated $17-\mathrm{OH}$ response to ACTH with little expected change in cortisol. The phenotypes of patients with the putative 21hydroxylase deficiency show a large degree of polymorphism ${ }^{2}$ and cannot be distinguished from those of polycystic ovarian disease (PCOD). Ovarian aromatase ${ }^{13}$ and 17ketosteriod reductase ${ }^{14}$ have been identified as defects in PCOD and could theoretically be responsible for an increased $17-\mathrm{OH}$ response to ACTH. Perhaps these defects should be considered as well as partial 21-hydroxylase deficiency when an exaggerated $17-\mathrm{OH}$ response to $\mathrm{ACTH}$ is seen.

1 Chrousos GP, Loriaux DL, Mann DL, Cutler GB. Late onset 21-hydroxylase deficiency mimicking idiopathic hirsutism or polycystic ovarian disease. Ann Intern Med 1982;96:143-8.

2 Kuttenn F, Couillin P, Girard F, et al. Late-onset adrenal hyperplasia in hirsutism. N Engl J Med 1985;313:224-31.

3 New MI, Lorenzen F, Lerner A, et al. Genotyping steroid 21-hydroxylase deficiency: Hormonal reference data. 21-hydroxylase deficiency: Hormonal

4 Ferriman D, Gallwey JD. Clinical assessment of body hair growth in women. J Clin Endocrinol Metab 1961;21:
a 1440-7.

5 Best WR, Mason CC, Barron SS, Shepherd HG. Validation of procedure for setting normal limits on basis of total laboratory experience. Clin Chim Acta 1970;28:127-32.

6 Werner M, Steinberg WM, Pauley C. Strategic use of combined enzyme indicators for acute pancreatitis analyzed by receiver-operator characteristics. Clin Chem 1989;35:967-71.

7 Scully RE, Mark EJ, McNeely WF, McNeely BU. Case record of the Massachusetts General Hospital. N Engl J Med 1988;318:1449-57.

8 Lobo R, Goebelsmann U. Evidence for reduced 3B-olhydroxysteroid dehydrogenase activity in some hirsute women thought to have polycystic ovary syndrome. J Clin Endocrinol Metab 1981;53:394-400.

9 Pang S, Lerner AJ, Stoner E, et al. Late-onset adrenal steroid 3B-hydroxysteroid dehydrogenase deficiency. I. A cause of hirsutism in pubertal and post-pubertal women. $J$ Clin Endocrinol Metab 1985;60:428-39.

10 Lobo R, Goebelsmann U, Horton R. Evidence for the importance of peripheral tissue events in the development of hirsutism in polycystic ovary syndrome. J Clin Endocrinol Metab 1983;57:393-7.

11 Kirschner MA, Samojlik E, Szmal E. Clinical usefulness of plasma androstanediol glucuronide measurements in women with idiopathic hirsutism. J Clin Endocrinol Metab 1987;65:597-601.

12 Milewicz A, Vecsei P, Schatz S, et al. Development of plasma 21-deoxycortisol. Radioimmunoassay and
applications to the diagnoses of patients with 21-hydroapplications to the diagnoses of patients with 21-hyd
xylase deficiency. $J$ Steroid Biochem 1984;21:185-91.

13 McKenna JT. Pathogenesis and treatment of polycystic ovary syndrome. N Engl J Med 1988;318:558-62.

14 Pang SY, Softness B, Sweeney WJ, New MI. Hirsutism, polycystic ovarian disease and ovarian 17-ketosteroid reductase deficiency. $N$ Engl J Med 1987;316:1295-301. 